\title{
Research on Quality Evaluation of Attribute Mathematical Model
}

\author{
Fangfang $\mathrm{Fu}^{1}$ \\ ${ }^{1}$ Nanchang Institute of Science \& Technology, Nanchang, Jiangxi, 330108 \\ 346591653@163.com
}

KEYWORDS: Quality Evaluation; Attribute Mathematics; Research Model

\begin{abstract}
This paper presents a mathematical model evaluation. The model consist of three parts: single index attribute measure analysis, multi-index comprehensive attribute measure analysis, attribute recognition analysis. We analyzed the differences in the properties and fuzzy mathematical model mathematical models. Application examples show attribute mathematical model is more reasonable.
\end{abstract}

\section{Introduction}

Establishment of a socialist market economic system and gradually improve and the accounting work of the new requirements, but also created favorable conditions for the accounting reform and development. But we should also see that many of the current problems can not be ignored accounting work does exist, if not required to deal with accounting issues, resulting in a lack of authenticity and reliability of accounting, accounting information and provide a serious distortion of accounting information. Those accounting quality problems harm to society are greater than the quality of the goods, seriously disrupting the social and economic order, interfering with the implementation of the country's reform and opening-up policy. Therefore, the evaluation of accounting quality, rectify accounting work order improve the quality of accounting work, give full play to the role of accounting in maintaining the market economic order of the socialist market economy is very important.

\section{The Status of Quality Evaluation}

Recently, the Ministry of Finance released a report on the quality of accounting information of 2007 test results in some industries. Investigation showed that the inspected units distortion assets and profits decline, but false credentials (accounting fraud (false statement (false audit (false evaluation) five false problem can not be ignored.

The checks related to medicine (Textiles (Civil Aviation (Metallurgy (petroleum and petrochemical industry, 320 enterprises and institutions, and to whom the audit report issued 125 accounting firms. Examination revealed to be untrue sampling unit assets 7.375 billion yuan, profits untrue 3.511 billion yuan. Some enterprises and institutions accounting information distortion is more serious. Some units reach profitability (enjoy) Debt Shipping (small group interests (listed on the packaging (a performance leader purposes, be adjusted consolidated financial statements range, a huge hidden losses, artificially adjusted profits. the spot checks found that now artificially adjusted profit (profits and losses of 32 companies, a total profit of 1.37 billion yuan artificially adjusted, which inflated profits of 1 billion, profits of 370 million virtual cut also part of the financial institution management confusion, lack of an effective internal control system and 
peripherals account (repeated illegal accounts and other issues. sampling results also showed that accounting firms audit quality varies greatly. some firms do not implement the necessary audit program, issued the audit report inappropriate, especially for the 32 Profits and losses of the business firm issued audit reports are recognized to varying degrees on the company's virtual surplus real loss. in order to avoid part of the CPA audit responsibilities with reservations or with instructions unqualified audit report instead of a negative audit report.

\section{Multi-index Comprehensive Evaluation Method}

For comprehensive evaluation process is a multi-dimensional space, the equivalent of the object being evaluated a number of points in multidimensional space, each index is equivalent to measure, evaluate the scale is different latitudes things. From single index (a dimension), the objects are evaluated to compare the sort, but not real scheduling problems for comprehensive evaluation process, but several vectors scheduling. From a mathematical point of view principle, multi-index comprehensive evaluation method is actually carried out two "mapping." Suppose that indicators constitutes a space $\mathrm{A}$, then $\mathrm{A}$ is the dimension of space, each dimension has a specific dimension, and each dimension is not the same as the first one is the actual value of the object assessment indicators on decision space mi ma a point ai.

Index comprehensive evaluation dimension treatment, the actual value of the index into the evaluation index value, which is in fact made a map, the more $\mathrm{f} \mathrm{A}$ space is mapped to the space $\mathrm{B}$, ie $\mathrm{f}: \mathrm{A} \rightarrow \mathrm{B}$, B space still m-dimensional, but each dimension between the dimension has been in agreement. By mapping $\mathrm{f}$, space $\mathrm{A}$ will be mapped to a point in space $\mathrm{B}$, that is.

For comprehensive evaluation of the synthesis process, in fact, it made a second mapping $\phi$, mapped again to the space B space $C$ ( $C$ space is actually a one-dimensional straight line) on, that $\phi: \mathrm{B} \rightarrow \mathrm{C}$. By mapping $\phi, \mathrm{b}$ space $\mathrm{B}$ on the map and to point $\mathrm{c}$ on the line $\mathrm{C}$, that is: $\mathrm{b} \rightarrow \mathrm{Ci}$.

\section{The Basic Content of Attribute Comprehensive Evaluation}

Comprehensive evaluation comprehensive evaluation system can be used to describe. Input system for the measurement of the sample index, comprehensive evaluation system can be divided into three subsystems: the relationship according to the size and type of evaluation index values determined performance function, and according to the measurement values of the second sub-system is a comprehensive multi-index performance analysis function, the function of each single performance indicators for the third sub-systems analysis to identify, according to a second sub-system output above problems can be seen as a comprehensive evaluation system for integrated decision-making system problems or issues. In this paper, the performance is as a function of attribute measure. Let $\mathrm{X}$ for the study of all known object space. Certain kind of nature we have to study the nature of the elements of $\mathrm{X}$ denoted $\mathrm{F}$, called the attribute space. For example, the teaching faculty evaluation, $\mathrm{X}$ is the set of all participating units, or $\mathrm{X}$ is one or a few indicators measure the value of each participating unit collection. We want to study the various teaching units teaching situation, you can make $F=\{$ Rank $\}$. Attribute space $F$ in a situation known as a set of attributes, for example: $=1 \mathrm{C}$ excellent $\},=2 \mathrm{C}\{$ good $\},=3 \mathrm{C}\{\mathrm{in}\},=4 \mathrm{C}\{$ poor $\}$, which are $\mathrm{F}$ (Rank) a case, attributes are set and it can be viewed as a subset of $\mathrm{F}$.

\section{Attribute Synthetic Assessment Model and Application Quality Evaluation}

Assessment of Quality is a more complex task, is affected by many factors, both with regard to teaching attitude, teaching content, teaching methods and the quality of teachers themselves, also 
involves learning state, but also to school spirit, school conditions, social ethos and policies, effective implementation of teaching quality monitoring, objective, impartial and scientifically to evaluate teaching quality, which not only beneficial to steadily improve teaching quality, but also conducive to teaching and fully mobilize the enthusiasm. Therefore crucial to establish a reasonable evaluation system, establish a scientific and effective evaluation system is the basis for the evaluation of teaching and prerequisites.

Subject evaluation is diversified, open, including experts, peer teachers, students, and other teachers themselves. As a classroom audience, students evaluate the most direct and accurate, it can be observed at any time by teaching effectiveness of teachers, student teachers can also collect a variety of classroom teaching experience frequent, and often only spend a short teaching evaluation to complete the anonymous questionnaire response. Therefore, teaching evaluation activities are fairly valued at current teaching evaluation, almost all colleges and universities have carried out teaching evaluation teaching evaluation activities. Another aspect of the evaluation of teaching teaching evaluation of teaching management or experts, also received considerable attention, but the teaching staff or administration experts rarely have the opportunity to participate in direct contact with classroom teaching, it is difficult to grasp the actual teaching dynamic, it is difficult to make an objective and impartial evaluation of the overall teaching quality.

So far, the evaluation of teaching another very important aspect - teaching peer evaluation of teachers, still did not get enough attention and use, including the contents of the evaluation program for undergraduate teaching Ministry of Education, has little to involve relevant content. Mainly refers to the professional, or engage in similar courses of the Department of teaching and research related to the evaluation of teacher peer Course. Evaluated as an important aspect of teaching evaluation, with other evaluation methods do not have the advantage, mainly in the following two aspects:

Peer teachers teaching content, teaching methods are very familiar with, it is possible for the implementation of the outline, teaching content, manner and speed of progress made pertinent comments. Teachers in the peer evaluation process, you can exchange ideas with each other teaching methods, academic insights and promote the improvement of teaching level.

Thus, you can get a double effect through peer evaluation of teachers, deserves attention. In this study, in consideration of the relevant content peer evaluation of teachers, and the original teaching evaluation index system had been amended, and the implementation process made some of Teaching Evaluation Peer evaluation of teachers.

\section{Recommendation for Quality Evaluation}

According to the accounting quality attributes estimation model established in this paper, we should standardize the accounting management, improve the quality of accounting and financial management to start, focus on the following aspects of work.

Grasping construction accounting system, improve the operating basis. Uniform accounting practices, mode change longstanding diverse fundamentally - piecemeal basis operating conditions, development of accounting rules and a series of operational methods of accounting - regulations. Grab business training and improve the quality of business accounting personnel. At the same time strengthen the internal training, accounting practitioners do re-education. Grasp construction laws and regulations to prevent operational risks. At least twice a year to organize a comprehensive inspection and a comprehensive accounting of special accounting checks to detect potential risks accountant, to take effective measures to control. Grab business innovation and accounting model innovation, extended accounting function, improve accounting standards. Set up financial 
accounting center, centralized accounting of financial costs. To strengthen the management and assessment of accounting staff and ensure the effective implementation of the system of financial laws and regulations. On the basis of extensive research, develop and organize the implementation of the accounting staff assessment of incentives and disincentives, from traffic - one by one development of quantitative indicators, service satisfaction rate, mobilize the enthusiasm of employees accounting - Business error rate. Loopholes, eliminate the potential risks and increase risk factors accounting management controls, such as disabled obsolete important blank vouchers and stamp business to clean up the destruction. Grasping services and strives to standardize, meticulous and thoughtful. The development of relevant measures and service standards, and consciously accept the supervision and appraisal service objects. Grasping personnel training, and build a good accountant and financial management team, listened carefully to reflect the accounting integrated business system, integrated business accounting systems to further improve the comprehensive summary and computerized accounting standards.

\section{Conclusion}

Given the current poor condition of the existence of accounting quality, strengthen management, improve the quality of accounting is imperative, but not only improve the quality of accounting to create a favorable external environment to regulate and manage more essentially from the macro from, paper, property accounting quality mathematical model element object space according to the measurement evaluation index, which element classification or classified as a class evaluation, so as to strengthen the quality of management accounting. Improve the quality of accounting provides a good platform, concludes with recommendations based on the evaluation model for the future needs to be done.

\section{REFERENCE:}

[1] T. D. Erwin, P. A. Knight. Transatlantic View of Assessment and Quality in Higher Education [J]. Quality in Higher Education. 1995, 1(2):179 188.

[2] J. Webster, P. Hackley. Teaching Effectiveness in Technology-Mediated Distance Learning [J]. Academy of Management Journal, 1997, (40):282 1309.

[3] J. Brennan, P. Devries, W. Ruth. Standards and Quality in Higher Education Institution [J]. Jessica Kingsley Publishers, 1997: 260 268.

[4] C. E. Shannon. A Mathematical Theory of Communication [J]. BSTT, 1948, 27:379 423. 